Volume 1

Issue 1 -- Melanoma Research

Article 1

2-28-2014

\title{
Welcome to the Journal of Patient-Centered Research and Reviews
}

Nick Turkal

Randall S. Lambrecht

Follow this and additional works at: https://aurora.org/jpcrr

Part of the Medical Education Commons

\section{Recommended Citation}

Turkal N, Lambrecht RS. Welcome to the Journal of Patient-Centered Research and Reviews. J Patient Cent Res Rev. 2014;1:6. doi: $10.17294 / 2330-0698.1003$

Journal of Patient-Centered Research and Reviews (JPCRR) is a peerreviewed scientific journal whose mission is to communicate clinical and bench research findings, with the goal of improving the quality of human health, the care of the individual patient, and the care of populations.

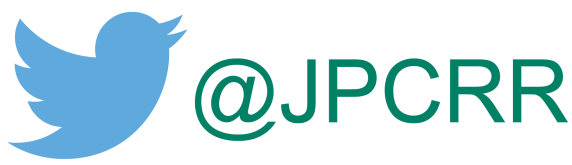




\section{Patient-Centered Research and Reviews}

Nick Turkal, MD/Randall S. Lambrecht, PhD

It is with great pride that we present the inaugural issue of the Journal of Patient-Centered Research and Reviews (JPCRR) focused on scholarly works devoted to improving patient care through research and discovery. We express our sincere congratulations to Dennis Baumgardner, MD, first editor-in-chief, along with his scientific advisory board and editorial team, for months of hard work leading up to the launch of this publication.

This amazing opportunity began almost a year ago, when the Temkin family made a generous gift to support this endeavor. In accord with our mission of JPCRR,

\section{"We recognize an ethical obligation to communicate original research findings for patients and the medical and scientific communities."}

they understand the importance of capturing and communicating the findings of scientific advancement broadly in a peer-reviewed journal, and we are grateful for their commitment. A quarterly journal, JPCRR will be published online and accessible worldwide. Articles will be from researchers within Aurora as well as from members of the global scholarly community.

As a large integrated health care system conducting clinical investigations, we recognize an ethical obligation to communicate original research findings for patients, and the medical and scientific communities, in the hope of improving quality outcomes. The scope of JPCRR will be interdisciplinary with a focus on information that helps improve patient care. This is consistent with Aurora's purpose statement: We Help People Live Well. It is what we do every day. And it speaks to a model of care informed by evidence-based research and innovation.
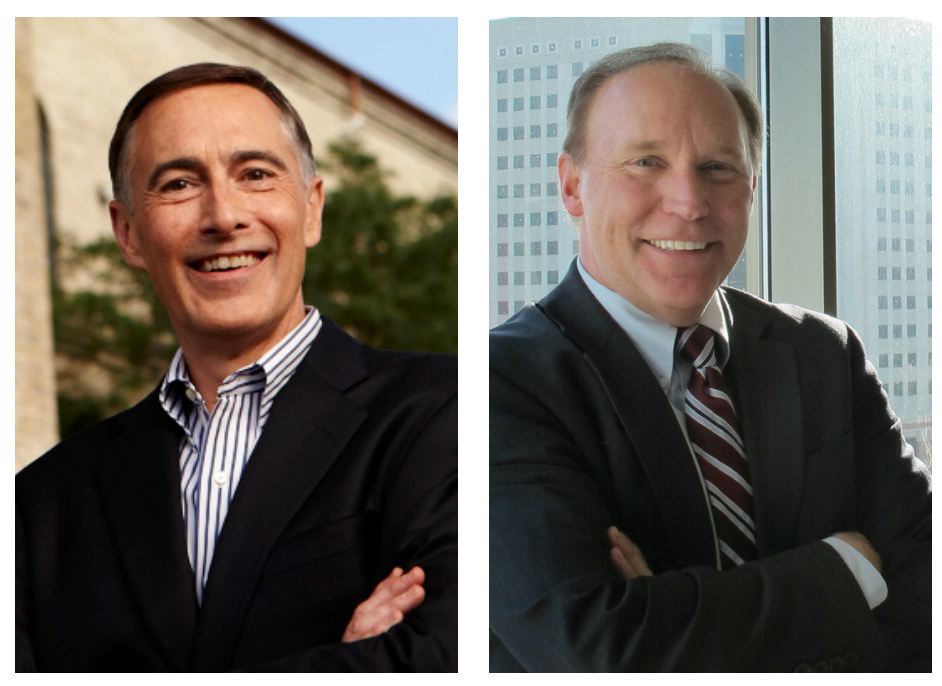

We look forward to JPCRR reporting major advances in all areas of patient care, including prevention and wellness, basic science investigations, developmental therapeutics in model systems, early translational studies in patients, and clinical trials. Original review articles will also include topics important to the health of populations.

It is our hope that JPCRR will serve as a vehicle for promoting research collaborations, which forge thinking between disciplines and embrace innovative ideas. We look forward to the many contributions our talented research caregivers, and colleagues from around the world, will make in the effort to provide the best patient care.

Regards,

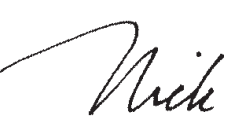

Nick Turkal, MD CEO \& President Aurora Health Care

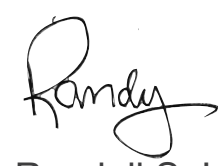

Randall S. Lambrecht, PhD Senior Vice President Aurora Health Care President Aurora Research Institute 